\title{
Cultura, dominação e sujeitos sociais
}

\author{
SYLVIA GEMIGNANI GARCIA
}

\begin{abstract}
RESUMO: Neste artigo, exponho algumas linhas mestras de uma abordagem que enfatiza a dimensão simbólica das relações de dominação e a ambigüidade da consciência dominada na produção acadêmica brasileira recente. Em seguida, discuto a crítica ao irracionalismo dessa perspectiva analítica e delineio, em oposição à primeira, a crítica ao comprometimento de tal enfoque com diretrizes racionalistas de concepção dos sujeitos sociais. Finalizo a discussão indicando as potencialidades desse tipo de abordagem no cenário das reflexões contemporâneas sobre os sujeitos sociais e políticos.
\end{abstract}

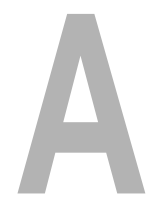

partir dos anos 60, um intenso movimento de questionamento teórico e metodológico dinamiza o campo da investigação científica dos fenômenos sociais. No bojo de um amplo processo cultural de crítica da sociedade moderna, que dá visibilidade aos limites e perversões da civilização ocidental em relação a seus próprios princípios e objetivos, constitui-se o mais recente momento de inflexão na história das ciências sociais, quando a vinculação entre simbólica e poder torna-se um dos traços distintivos do pensamento nessas disciplinas.

Embora não se trate de caracterizar esse movimento de forma unívoca, não há dúvida que a questão das relações entre estrutura e sujeito configura-se como um de seus traços distintivos. Nesse âmbito, ele define-se pela articulação entre cultura e política, baseada na consideração da heterogeneidade social das representações e das experiências vividas, que se afirma contrapondo-se diretamente a um enfoque identificado pela prioridade analítica concedida às estruturas, à ordenação nacional-institucional da
UNTERIVIOS:

cultura, dominação, sujeito, estrutura, ordem social, sociologia, antropologia, Brasil.

Professora do Departamento de Sociologia da FFLCH-USP 
sociedade e à determinação objetivista das identidades, esta última associada à representação da ordem social em termos de uma sociedade do trabalho na qual as identidades definem-se em função de interesses determinados por posições estruturais. Caracteriza-se, assim, uma das configurações abrangentes através da qual o Ocidente contemporâneo distingue-se de um passado recente, recortando a modernidade em dois tempos e delineando os termos da problemática do sujeito na atualidade.

No Brasil, essas transformações começam a tornar-se mais visíveis na produção acadêmica em fins dos anos 70, associadas a alguns fatores especificamente políticos. O mais evidente deles é a emergência, na mesma época, de novos fenômenos políticos na sociedade brasileira, isto é, o surgimento de movimentos sociais e reivindicatórios, no bojo do processo de “transição democrática"(cf. Magnani, 1981; Montes, 1983; Lopes, 1984 e Paoli, 1987). Além disso, é possível delinear uma correlação, como o faz Eder Sader, entre as mudanças intelectuais do fim da década de 70 e as derrotas sofridas por ocasião do golpe militar de 1964 e aprofundadas em 1968. Dessa ótica, os novos referenciais teóricos aparecem como um "efeito retardado e mais profundo das derrotas dos anos 60" (Sader, 1988, p. 33). que ganham visibilidade total em fins dos anos 70 quando movimentos contestatórios dinamizam a cena política, enfraquecendo o sentimento generalizado de impotência produzido pela instauração do regime militar que dificultava a constatação da ocorrência de deslocamentos analíticos fundamentais.

Cabe, entretanto, ressaltar que os novos referenciais teóricos afirmam-se em contraposição direta ao paradigma analítico então vigente, orientador de um tipo específico de interpretação da realidade político-social brasileira. Esse confronto expressa-se, desde logo, na caracterização das novas abordagens em termos de redescoberta da importância da dimensão simbólica para o estudo das relações de dominação.e da heterogeneidade do social. A força dessa diretriz se configura no enfrentamento com um sistema analítico basicamente objetivista que concebe o social como estrutura, com base em uma representação da sociedade como natureza (a natureza social do homem), e direciona a investigação para as formas de produção e reprodução da ordem social.

Para expor alguns aspectos desse processo de reapropriação analítica da problemática do sujeito e da ação social na produção acadêmica brasileira, utilizo-me de um pequeno conjunto de textos que expõem referenciais básicos do enfoque que orienta um vasto conjunto de pesquisas sobre tradições, crenças, formas de lazer, gostos, opiniões, costumes, em suma, um conjunto variado de fenômenos no qual se investigam os modos de vida de camadas sociais subalternas tematizando a questão da dominação e da resistência ou da ordem e da negatividade social. 


\section{As práticas, o presente e uma nova política}

A possibilidade de articular a análise da dimensão simbólica ao estudo da dominação concretiza-se através da concepção da cultura e da política como campos de práticas, isto é, espaços dinâmicos que se constituem continuamente pela ação dos sujeitos sociais; lugares que admitem, portanto, certo nível de indeterminação. Abordando essas discussões é possível expor modos de conceber a política que implicam a consideração dos universos simbólicos e, inversamente, de conceber a cultura incorporando dimensões sóciopolíticas. Através deles, é possível acompanhar a convergência de perspectivas das reflexões sobre a classe social, no campo da sociologia, e sobre.a cultura, no terreno da antropologia.

Como exemplo do primeiro movimento, utilizo-me da discussão de Sader e Paoli (1986) do modelo de análise da classe operária brasileira construído pelos acadêmicos a partir dos anos 50. Suas pesquisas sobre os trabalhadores urbanos e fabris - que se inserem no conjunto de preocupações postas pela temática da modernização - constroem um modelo cujo principal traço é a negatividade da classe operária brasileira, caracterizada de um modo que a descreve, afinal, como uma classe que ainda não o é. Apesar de viverem na cidade, incorporados ao mercado de trabalho capitalista, os trabalhadores fabris repõem o universo rural, arcaico e inculto. O paradoxo é explicado pela debilidade da industrialização brasileira, incapaz de produzir a racionalidade capitalista. A conclusão é que o vir a ser da classe repousa na possibilidade do desenvolvimento industrial que criaria as condições infra-estruturais adequadas à constituição do proletariado como classe, isto é, com consciência de classe ${ }^{1}$.

O fundamento dessa imagem de classe está, portanto, em abordá-la enquanto sujeito estritamente determinado por uma lógica global definida pelas "condições objetivas de existência". A rejeição dessa perspectiva afirma que seu limite está em desconsiderar que o modo como os homens vivem tais condições objetivas depende do significado que atribuem a essas condições. Recuperar o alcance da dimensão simbólica para a constituição dos sujeitos coletivos exige o abandono de uma abordagem que explica a atuação dos trabalhadores enquanto resultado de determinações estruturais externas à classe e independentes dos homens, produtora de uma configuração unitária e teleológica de classe.

Incorporando a dimensão simbólica ao modo de conceber o processo de reprodução social, tende-se a uma representação da sociedade constituída por divisões, comportando um ou vários princípios de contestação, e menos a uma concepção da sociedade como totalidade integrada na qual, tal como em um organismo, uma máquina ou um sistema, cada elemento específico definese por sua funcionalidade em relação ao todo. Trata-se de um aspecto da crítica ao entendimento mecânico da reprodução social, enquanto processo assegurado pela dinâmica das estruturas.

1 Ver também Sader, Paoli \& Telles (1984). 
Sinteticamente, pode-se apresentar os principais resultados dessa abordagem nos seguintes termos:

1- uma representação do social constituído por divisões, cuja manutenção é menos um dado do que uma possibilidade reatualizada em um processo contínuo de luta, no lugar de uma concepção da sociedade como totalidade integrada onde cada elemento específico define-se por sua funcionalidade em relação ao todo; $\mathrm{e}$

2- uma concepção de classe como experiência que se constitui em múltiplas dimensões da existência que não se referem exclusivamente, nem mesmo principalmente, à esfera da produção, mas recobrem campos variados que englobam todo o modo de vida dos trabalhadores. Vida familiar, redes de lazer, práticas religiosas, dimensões plurais do cotidiano revelam-se espaços privilegiados para a pesquisa das formas e significados das representações de mundo dos dominados.

Afastando-se da correlação entre posição de classe no sistema produtivo e expressão da consciência de classe na esfera política institucionalizada - através de partidos e sindicatos -, essa abordagem descobre esferas de importância então insuspeitada para a concepção da identidade de classe e, ao mesmo tempo, já não prioriza a pesquisa do setor mais avançado, isto é, o operariado industrial. Dando conta da extraordinária diferenciação interna que caracteriza o contingente de despossuídos de riqueza, status e poder da sociedade brasileira na cidade e no campo, a pesquisa aborda, agora, menos a classe operária do que as "camadas populares". Trata-se de uma categoria descritiva que, entretanto, funciona no debate como um contraconceito que marca a diferença de abordagem em relação ao enfoque macroestrutural.

Tendo em vista o desenvolvimento posterior da discussão, é preciso enfatizar desde logo o caráter relativo dessa crítica. Nos termos de Sader, a adoção de uma tal perspectiva não pode significar a afirmação de uma vontade soberana dos sujeitos que - como produtos sociais que são - "estão implicados nas estruturas objetivas da realidade" (1988, p. 45). Trata-se de incorporar a indeterminação como uma dimensão constitutiva da ação social, através da qual uma "capacidade criadora da imaginação produz novos significados" (Sader, 1988, p. 46). Mas não se deve entender com isso que o indeterminado recobre todo o real. Nesse sentido, a vida cotidiana continua sendo entendida como espaço da reprodução social. Nos termos de Francisco de Oliveira, porém, tal reprodução "não é simplesmente o eterno retorno da produção, que no caso transformaria os resultados em reposição dos pressupostos. A reprodução é o movimento no qual e pelo qual a objetividade se representa" (1987, p. 12) $)^{2}$.

Se as colocações acima tratam de um modo de pensar a classe através de um enfoque que dá destaque às representações simbólicas na constituição de identidades coletivas, Eunice Durham (1977), no texto brasileiro mais citado na literatura em questão, faz o caminho inverso, servindo aqui 
GARCIA, Sylvia Gemignani. Cultura, dominação e sujeitos sociais. Tempo Social; Rev. Sociol. USP, S. Paulo, 8(2): 159-176, outubro de 1996.

como representante exemplar de um modo de conceber a cultura que incorpora a problemática política e social, em contraposição ao modelo então predominante no cenário intelectual brasileiro.

Nas teorias da modernização e nas pesquisas sobre a atuação política e sindical dos trabalhadores dos anos 50 e 60, Durham não identifica um modelo negativo de classe, e sim um conceito reificado de cultura. Segundo a autora, imputando à dimensão cultural um conteúdo normativo que lhe confere uma autonomia inadequada, aquelas pesquisas apresentam os fenômenos culturais como padrões tradicionais aos quais os indivíduos apegam-se irracionalmente e que resistem inexplicavelmente numa organização social moderna. A origem rural dos trabalhadores explica os defeitos do sindicalismo, a falta de consciência de classe e a baixa produtividade industrial. Entretanto, a adoção ou persistência de padrões culturais "não constitui explicação de nenhum fenômeno social, mas são em si fenômenos que devem ser explicados na análise do processo de transformação social. [...]. Padrões culturais sobrevivem na medida em que persistem as situações que lhes deram origem, ou alteram seu significado para expressar novos problemas" (Durham, 1977, p. 33). O pressuposto da explicação que está sendo questionada é, segundo a autora, uma concepção na qual a cultura aparece como produto, sem que se considere o "modo pelo qual é produzida" (Durham, 1977, p. 33).

Considerar esse modo de produção é a abordagem necessária para tratar da dinâmica cultural nas sociedades modernas. A partir da afirmação da "unidade fundamental entre ação e representação", Durham concebe a cultura como processo pelo qual os homens orientam e conferem significado às suas ações, definindo a análise cultural como a investigação sobre a contínua "reorganização das representações na prática social, representações que são simultaneamente condição e produto dessa prática" (Durham, 1977, p. 34). Discutindo, nesses termos, a heterogeneidade cultural nas sociedades modernas, que é decorrente da distribuição desigual do trabalho, da riqueza e do poder, a autora afirma a exigência analítica da consideração da dimensão política da cultura: a diversidade cultural é expressão de oposições que repercutem na dinâmica das relações de classe, na medida em que formulam interesses divergentes.

O ponto a enfatizar é que a crítica à atribuição de uma autonomia inadequada à dimensão cultural dirige-se à explicação das ações sociais como conseqüências de representações simbólicas, concebidas enquanto conjunto dado de costumes, valores e comportamentos herdados que asseguram a continuidade de um grupo social, isto é, comandam sua reprodução. A ênfase no aspecto ordenador da dimensão simbólica aparece, assim, como limite da teoria estruturalista da cultura. A abrangência teórica alcançada pelo nível de abstração com que opera a análise da lógica interna dos sistemas simbólicos tem por contrapartida a ausência da consideração da realidade social, rede de relações na qual seria possível observar a dinâmica histórica. Utilizando as palavras de Ortiz, na perspectiva estruturalista, "as organizações sociais são 
na verdade atualizações lógicas do grupo de transformações deduzido do modelo estrutural" (1980, p. 78).

Mas a afirmação da unidade entre ação e representação no âmbito das reflexões culturais atinge ainda a concepção da cultura como produto determinado pelas estruturas econômicas, característica de uma vertente do pensamento marxista. Conforme essa abordagem, a cultura corresponde a um conjunto de aparências que a análise deve ultrapassar buscando, por trás delas, causas "mais reais" dos fenômenos sociais e políticos, de acordo com uma hierarquia de níveis - economia, sociedade e cultura. Quanto mais profundo o nível, mais poderoso como determinante do real. Mudanças econômicas produzem transformações sociais e seqüencialmente alterações nas idéias e costumes. Chega-se sempre às causas finais, os fatores econômicos, isto é, a condição em relação à propriedade dos meios de produção. Privilegiando o "real", essa perspectiva tende a considerar a cultura como reflexo superestrutural de causas eficientes externas e independentes das dimensões simbólicas. Duglas Teixeira Monteiro comenta o problema na introdução ao seu estudo da Guerra Santa do Contestado. Segundo ele, a ênfase na consideração das "condições objetivas" para a explicação dos fenômenos de "fanatismo religioso" no Brasil levou, em geral, a explicações do tipo "em última análise", fórmula que "pode significar a perda do humano e social concretos" (1974,p. 12). Segundo Duglas, tendendo a ver a dimensão religiosa como epifenômeno que esconde o essencial, isto é, os "fatos" sobre os quais a construção ideológica sobrepõe-se, a análise distingue e separa uma dimensão material - objetiva - e a esfera das representações - fantasmagoria -, deixando de considerar que os fatores materiais mesclam-se às representações que deles fazem os agentes sociais.

$\mathrm{Na}$ articulação entre ação (fazer histórico) e representação (reprodução social) reside a possibilidade de recuperar analiticamente a dinâmica das relações sociais, afirmando o caráter criativo dos universos simbólicos que se concretiza nos modos como se inserem em campos de práticas. Desse modo, a cultura é sempre processo, em constante reatualização. Todo e qualquer ato dos sujeitos de ações significantes corresponde à dinamização do universo cultural: reposição, reelaboração ou alteração dos sentidos existentes.

A dimensão simbólica deixa de ter um sentido único, definido fora do âmbito das condutas humanas, e passa a ser pensada em termos de heterogeneidade e polissemia. A estrutura não desaparece mas é dinamizada, inserindo a problemática cultural no campo das relações político-sociais. Os parâmetros estruturais dados funcionam como uma matriz lingüística a partir da qual constituem-se múltiplas falas. Sua pluralidade não corresponde simplesmente às possibilidades lógicas de um sistema de comunicação, mas às divergências de perspectivas dos vários grupos sociais que vivem em condições desiguais de existência. A heterogeneidade dos discursos culturais expressa a diversidade de pontos de vista que caracteriza uma sociedade 
GARCIA, Sylvia Gemignani. Cultura, dominação e sujeitos sociais. Tempo Social; Rev. Sociol. USP, S. Paulo, 8(2): 159-176, outubro de 1996.

transpassada por desigualdades. Para seus agentes, a prática discursiva é o instrumento no qual e pelo qual constroem e expressam seus interesses.

Na recuperação analítica da criatividade da ação humana através da relativização da determinação infra-estrutural e da ênfase nos sistemas inconscientes de articulação dos símbolos encontramos modos do pensamento contemporâneo reagir a certa configuração da teoria nas ciências humanas e sociais que praticamente retirou do horizonte da análise o homem como agente histórico. Usando imagens espaciais, teríamos: "abaixo", as contradições estruturais entre forças produtivas e relações de produção conforme uma teoria do capital; "acima", os nexos estruturais articuladores de símbolos conforme uma teoria da cultura. "No meio", a impossibilidade da criação humana coletiva, seja porque a história se faz em outro lugar, seja porque não há história mas a repetição eterna do sempre igual.

A redescoberta teórica do momento da intervenção humana no real constitui a importância da dimensão política da vida social. Imersos nas redes de práticas sociais, os universos simbólicos tornam-se loci privilegiados das relações de poder, onde se estabelecem consensos e confrontos, lugar da obediência e da resistência, da aceitação do outro e da afirmação de si. Para tal proposição, o sentido da experiência cotidiana não se limita à reprodução da ordem social instituída. Se os sistemas simbólicos são efetivamente produtos sociais, comportam simultaneamente uma dimensão positiva e dinâmica; eles têm a potencialidade de, articulados pelos homens, intervir na ordenação do mundo alterando significados. Por essa via a ordem social deixa de ser vista como um contínuo totalmente estruturado; comporta brechas e fissuras, espaços potenciais de contestação. Heterogeneidade e diversidade caracterizam um discurso que descreve o social como fragmentação. Na sua perspectiva, o predomínio da "cultura dominante" não é um dado, um poder plenamente instaurado, mas um projeto de poder que se impõe através de uma luta constante. Numa movimentação que não é totalmente determinada, todo espaço conquistado pode a qualquer instante ceder. O poder deixa de ser totalmente unificado, tendo no aparelho de Estado seu núcleo gerador. Dinamizado, ele torna-se múltiplo e circula, em sua pluralidade, nos mais finos meandros do tecido social como relação: confronto, resistência, cooptação.

Através da ótica dos agentes, que todavia não significa negação de toda determinação estrutural ou o elogio da diferença desprezando seu caráter de desigualdade, o enfoque intelectual que assim se afirma atinge, ainda, a idéia do "atraso" e da "alienação" como características definidoras da consciência e da cultura das camadas populares, como passo a expor sucintamente.

A concepção da cultura como campo de práticas abre o espaço para pensar positivamente o conservadorismo das camadas sociais dominadas. Mais uma vez, um dos textos mais representativos para essa questão é de Eunice Durham (1973), e discute uma aparente "resistência à modernidade" entre os migrantes nas cidades. Analisando os modos como os sujeitos vivem a 
Ver também Bilac (1978); Macedo (1979); Durham (1980, 1986) e Caldeira (1984).

4 Para isto ver Fernandes (1977, 1989); Branco (1982); Candido, (1987) e Pécaut (1990). experiência da migração, a autora questiona o entendimento do fenômeno urbano como instauração do individualismo, da racionalidade e da impessoalidade. A passagem do rural ao urbano define-se como processo de aprendizagem de padrões que regulam a comunicação em sistemas complexos; uma aprendizagem que se realiza, basicamente, no interior de grupos primários através da comunicação direta de experiências ${ }^{3}$.

O traço essencial a destacar em sua análise refere-se a uma inversão de diagnóstico quanto ao problema da falta de participação dos trabalhadores urbanos em organizações políticas. A partir da perspectiva dos sujeitos da experiência, Durham nega a inadequação dos padrões culturais dos migrantes para a vida conforme a organização social moderna. Segundo a autora, inadequada é a ordem institucional através da qual se implanta a modernização no Brasil. Na ótica da modernidade, a conduta dos setores populares é inadequada à sociabilidade urbana. Do ponto de vista das condições de vida dos setores populares, as instituições urbanas são inadequadas à organização e expressão de suas experiências de vida.

Essa inversão de diagnóstico corresponde a uma mudança na forma de trabalhar as categorias função-disfunção e tradicional-moderno que abandona a representação da cultura como elemento gerador de obstáculos ao progresso. As diferentes temporalidades que se cruzam na organização social brasileira passam a ser descritas como o produto de práticas cuja positividade define-se em relação à experiência concreta de sujeitos sociais específicos. A "persistência" de padrões culturais tradicionais revela-se recriação de redes de sociabilidade. Além disso, eles não se apresentam mais como um fenômeno exclusivamente "mental", mas resulta do modo como os trabalhadores vivem sua condição social. Em suma: valores simbólicos são gerados por práticas, existem no presente e só existem porque funcionam, concretizando a possibilidade da experiência social com sentido.

Isso quer dizer que o passado que se reatualiza no presente não é:

1- um elemento residual em relação a um padrão de progresso que dita a direção para a qual, necessariamente, deve orientar-se a totalidade dos sujeitos inseridos em uma organização social moderna; e

2- um produto da reprodução do capital em sociedade dependente, onde funciona como agente da necessária reprodução das desigualdades que sustentam, a nível local, o desenvolvimento dos países dominantes no plano do mercado internacional ${ }^{4}$.

Nos trabalhos de Carlos Rodrigues Brandão, esse tipo de visão desdobra-se em uma concepção do tradicionalismo das camadas populares com um significado especificamente político, isto é, como resistência à dominação. O ponto de partida de sua abordagem está na definição da cultura popular como o trabalho social de sua produção. Pesquisando as redes sociais de criação e reprodução de saber de uma memória popular viva, o autor constrói uma leitura da cultura popular como um espaço de enfrentamentos, onde os dominados praticam estratégias de resistência política e cultural aos projetos 
de hegemonia do saber oficial.

A ênfase nos sujeitos que, como se vê, rearticula a questão da temporalidade da sociedade brasileira, descartando o "atraso" da cultura e da consciência das camadas populares, repercute também na questão da ideologia. A superação da análise dos fenômenos culturais populares enquanto expressão e veículo da alienação das classes dominadas é o outro ponto aqui abordado para situar a emergência da perspectiva analítica que articula cultura e política nos estudos acadêmicos das décadas de 70 e 80 no Brasil.

Quanto a esse tema, o debate articula-se em torno de duas concepções de ideologia: uma, que se define a partir da separação entre ação e representação produzida pela divisão social do trabalho no modo de produção capitalista; e outra que parte da consideração de que as idéias estão inscritas nas práticas dos homens (cf. Bruni, 1980) . $^{5}$.

Em texto representativo da problemática que situa os estudos das manifestações culturais populares em suas implicações sociais e políticas, $M$. Lucia Montes faz a crítica da primeira acepção de ideologia. Seu ponto de partida é a análise de uma concepção do poder que pressupõe a identidade entre a racionalidade da ciência e a racionalidade da ação política. Tal pressuposto projeta uma perspectiva para a qual os sujeitos políticos só constituem-se como tais à medida que alcançam a verdadeira consciência da classe a que pertencem. Antes disso, sua ação é inconseqüente ou, pior, prejudicial a seus próprios interesses. É, portanto, através da consciência que entende a racionalidade do real que os homens tomam conhecimento de sua situação no presente e deduzem os rumos da ação futura. Àqueles que não atingem a consciência verdadeira, resta a condição da consciência alienada. "O paradigma afirma, em última instância, que todo o real é racional e que só há ciência do que é real e racional. O que na ação política não puder ser assim explicado será [...] descartado como não-pertinente, ou 'explicado', ao preço de ser desqualificado, como conseqüência da ignorância-alienação. [...] ignorância que acaba por se confundir com a própria irracionalidade. Tal é, afinal de contas, o único estatuto que acaba sendo possível atribuir à dominação" (Montes, 1983, p. 16-17).

Entretanto, é preciso indicar, desde logo, a existência de um paradoxo. Em princípio, essa perspectiva afirma que toda ação postula um fim, impulsionada por uma vontade. Porém, no momento seguinte, essa vontade é transformada em cálculo entre meios e fins, dada a identificação entre a racionalidade da ciência e a do real. O elemento subjetivo transmuta-se em objetividade - o saber racional que é privilégio dos dominantes -, enquanto os dominados tornam-se "aqueles que não têm vontade". E, no entanto, o poder visa exclusivamente a vontade dos dominados, seja para apaziguá-la, seja para mobilizá-la. "É em seu nome [dos dominados] e para eles - quando não em lugar deles - que falam as solícitas minorias iluminadas que pretendem defendê-los ou esclarecê-los" (Montes, 1983, p. 22).

Segundo Montes, a questão da legitimidade do mando fica fora do

Ver também Ortiz (1978); Queiroz (1981) e Chauí (1984). 
alcance de uma tal abordagem. Ao contrário, ela é a questão nuclear da reflexão política de Antonio Gramsci sobre a ideologia. Enfatizando o caráter criador da luta de classes, através da qual os homens transformam as estruturas do real, Gramsci considera as super estruturas como a dimensão própria à ação que, assim, se realiza na e através da ideologia. Ao invés de reflexo da infra-estrutura, as superestruturas tornam-se "sua expressão concreta" (Montes, 1983, p. 42), que lhe dão forma social e institucional. Portanto, espaço onde circulam as dimensões do poder, nas quais ele se exerce e pode ser transformado.

A partir dessa teoria, a proposta de pesquisa de M. Lucia Montes é investigar as representações da sociedade e do poder que legitimam a ordem social do ponto de vista dos dominados. Para isso - ela afirma - é preciso penetrar nas dimensões da subjetividade, da afetividade, do não-racional, sem desqualificá-las a priori, reconhecendo um lugar para o irracional na história e na política. Mas, sem cair no elogio da irracionalidade, considerando que essa desrazão pode ser, apenas, "uma outra racionalidade" (Montes, 1983, p. 18).

A entrada nesse universo tem um pressuposto, fornecido pela teoria gramsciana. Nos termos de Montes, ao voltar-se para as representações dos subalternos, deve-se fazê-lo sabendo que "por definição, eles se regem pela lógica da ambivalência e da ambigüidade, ao dizer a um só e mesmo movimento o sim e o não, a dominação e seu contrário" (1983, p. 22).

A fragmentação característica da consciência dos dominados é o fundamento da tarefa que Gramsci atribui aos "intelectuais orgânicos” das classes subalternas: orientar a construção de uma vontade coletiva e coerente, vale dizer, uma "filosofia da práxis" que realizará a superação da dominação de classe (cf. Gramsci, 1978, 1979 e 1985). Com essa definição da filosofia crítica, Gramsci aproxima-a da idéia de religião que também fornece uma concepção de mundo coerente e abrangente. No sentido laico de "unidade de fé entre uma concepção do mundo e uma norma de conduta adequada a ela", política e religião identificam-se: "por que chamar 'religião' a esta unidade de fé, e não ‘ideologia’ ou, mesmo, 'política’?” (Gramsci, 1978, p. 14)

Três pontos fundamentais dessa diretriz podem ser assim sucintamente indicados:

1- ambigüidade das visões de mundo das camadas subalternas;

2- reformulação de uma função político-cultural do intelectual;

3- identidade entre política e religião; quero dizer, uma concepção da ação política a partir da crença que a impulsiona.

A ambigüidade das práticas culturais populares funciona, efetivamente, como ponto de partida de uma abordagem que abandona a problemática da verdade e do erro própria às análises que se utilizam da categoria "alienação". Conseqüentemente, ela não leva a uma representação do saber popular como uma outra cultura, contraposta à cultura dominante.

O predomínio da concepção da ambigüidade da cultura popular tem 
GARCIA, Sylvia Gemignani. Cultura, dominação e sujeitos sociais. Tempo Social; Rev. Sociol. USP, S. Paulo, 8(2): 159-176, outubro de 1996.

um bom exemplo em Brandão, justamente porque, como se viu, sua obra afirma com veemência o caráter de resistência à dominação das religiosidades populares que ele investiga. Sua ênfase na oposição entre religiosidades populares e eruditas e no sentido político das trocas no interior do campo religioso não permite perder de vista que, para ele, o poder das camadas dominadas é relativo, exatamente porque são classes subalternas às quais outras classes impõem sua direção. "A idéia de que subalternos da roça e da cidade transportam coletivamente o domínio popular do religioso para as brechas possíveis de serviços à classe e de trabalho político da classe não deve patrocinar a ilusão de que as religiões dos dominados são, sempre e de maneira autônoma, frações livres de uma cultura popular associada, por inteiro, a lutas de classe contra um estado social de dominância". Os "atos ativos de reconquista política e da criação cultural dos dominados" acontecem "nos espaços de tolerância do reino das regras impostas pelo comando exercido, na prática, por grupos eruditos de poder religioso ou profano" (Brandão, 1986, p. 300).

Estamos diante de uma interpretação para a qual os saberes populares são sistemas de conhecimento do mundo. Os grupos sociais subalternos criam e recriam representações de si e da sociedade numa operação simbólica instituinte da existência humana. Contudo, tais representações não expressam uma consciência alienada ou uma consciência verdadeira, mas expõem a divisão inelutável que caracteriza a experiência de vida dos dominados. Nem sábios, nem iludidos; dominados a um só tempo conscientes e conformados. Por definição, a cultura popular - na qual e através da qual se constitui essa ambigüidade - não é conservadora nem progressista. Seu sentido político depende de condições históricas específicas a partir das quais ela pode tender para uma direção ou para outra.

Nessa dubiedade reside um potencial indeterminado de ação que projeta a necessidade da organização política das camadas subalternas. Quer dizer, a função político-social dos intelectuais não desaparece com a emergência de uma nova abordagem do popular. Ao contrário, ela é retomada numa perspectiva que se propõe mais eficaz, para o que investiga os símbolos e os códigos próprios às representações de mundo das camadas populares em certo momento histórico em uma sociedade determinada: "evidentemente, não nos enganamos quanto à possibilidade transformadora das práticas populares. Sabemos que, sem condições reais que lhe permitam uma atuação política efetiva que tornem essas crenças um todo coerente capaz de 'cimentar uma nova hegemonia', essa concepção de mundo se encerra nas fronteiras do 'vivido', no sentido de que não consegue extrapolar os limites da compreensão individualizada das contradições. [...] Cabe a nós, talvez, pelo nosso olhar, que é o olhar daquele que vê de fora, tentar recuperar os elementos transformadores e dar-lhes uma coesão que poderá contribuir, quem sabe, para o surgimento desta "nova cultura das grandes massas populares' " (Montero, 1985, p. 10). 


\section{Racionalidade, crítica da razão e ambigüidade}

$\mathrm{Na}$ medida em que a diretriz que estou acompanhando aqui efetivamente se institui como matriz analítica para os estudos sobre as relações de dominação, ela suscita várias leituras críticas. Nos limites desta discussão, trato apenas daquelas que expressam, a meu ver, duas posições extremas relativas às formas de conceber os sujeitos sociais e que permitem, assim, delinear o espaço no qual se situa o enfoque ora em questão.

O primeiro tipo de crítica é sistematicamente formulado logo que um expressivo conjunto de trabalhos com a nova orientação começa a circular nos meios acadêmicos. Para apresentá-la aqui através de um bom exemplo utilizo-me de Simon Schwartzman. Seu ponto de partida é a distinção entre perspectivas analíticas racionalizantes - de entendimento crítico e que operam por abstração - e perspectivas que valorizam o elemento estético, enfatizando a importância da imaginação para a produção de um conhecimento baseado em uma relação "empática" com aqueles que, para a posição oposta, seriam os "objetos" da investigação. Dessa ótica, Schwartzman identifica nas pesquisas dos anos 70 e 80 sobre as camadas populares a expressão de uma nova diretriz da ciência social brasileira, inspiradora de um discurso que valoriza a emoção e a intuição, opondo-se ao "raciocínio frio e desumanizado, à tecnocracia e ao poder constituído em todas as suas formas" (1987a, p. 33).

Partindo de considerações a respeito da crise da sociologia e da citada correspondência entre o advento dos movimentos sociais e o interesse acadêmico pelo popular, o autor situa o redirecionamento de grande parte das ciências sociais para a investigação da nova realidade. Nesse movimento, os intelectuais, que quinze anos antes auto-proclamavam-se a consciência esclarecida na nação, "agora confessam humildemente sua ignorância e a necessidade de aprender com a gente simples. O povo, no novo discurso, sabe votar, é intrinsecamente democrático, tem uma sabedoria recôndita muito superior aos artificialismos da cultura importada. O intelectual agora assumia a tarefa de dar dignidade e respeitabilidade às coisas do povo - sua linguagem, sua religião, seus valores - e, a partir deste trabalho redentor, conquistar seu novo espaço" (Schwartzman, 1987a, p. 33). Isto é, o espaço do discurso que valoriza a imaginação e o sentimento em oposição à razão, à abstração e à crítica características da linguagem científica tradicional ou, nos termos do autor, "das ciências sociais academicamente constituídas" (1987a, p. 33).

Desse modo, Schwartzman faz a crítica do irracionalismo que enforma as abordagens que defendem a imaginação e a experiência vivida contra a ciência formal. Segundo ele, tal perspectiva é absolutamente inadequada para um país que precisa urgentemente aparelhar-se, tendo em vista uma adequação mínima ao mundo contemporâneo - aparelhagem esta que tem por base o desenvolvimento científico e tecnológico. Nesse sentido, defende um espaço institucional para as ciências sociais que as faça florescer na direção de uma produção de conhecimentos relevantes dentro do contexto 
GARCIA, Sylvia Gemignani. Cultura, dominação e sujeitos sociais. Tempo Social; Rev. Sociol. USP, S. Paulo, 8(2): 159-176, outubro de 1996.

brasileiro, caracterizado pela necessidade de tecnologias sociais que funcionem bem. Assim o autor alinha-se ao lado da modernidade numa batalha que considera quase perdida pela modernização da sociedade brasileira, diante da força das tendências anti-intelectualista dominantes no cenário acadêmico (cf. Schwartzman, 1987b e 1989) ${ }^{6}$.

Entendo, baseada na consideração das linhas mestras da abordagem dos fenômenos simbólicos articulados à questão das relações de dominação, que o reconhecimento da subjetividade como elemento constitutivo do real - da paixão que impulsiona a ação - não institui uma outra perspectiva cognoscente, de uma natureza diversa daquela da racionalidade da ciência social tradicional. Tal perspectiva analítica constrói-se desvelando um elemento contido na própria razão - e no entanto ocultado nas formulações objetivistas da realidade histórica, social e política. Não se trata, portanto, de uma razão à qual se opõe uma anti-razão, contrária ao intelecto, mas, antes, de um movimento racional de alargamento de suas próprias fronteiras.

Esse movimento produz:

1- uma crítica das perspectivas objetivistas da realidade histórica e social que, afinal, revela que elas não são plenamente racionais, mas possuem uma dimensão subjetiva oculta, na medida em que incorporam o potencial da subjetividade como um elemento da prática político-social, ainda quando tentam negá-lo. Como se viu na análise de Montes, ao conceber a vontade como saber, a ciência projeta a noção dos dominados como "os sem vontade" e, contudo, não pode abrir mão de considerar essa vontade neles quando pensa o problema do poder;

2- uma ampliação do campo do real cognoscível. A subjetividade incorporada ao campo de investigação revela-se, afinal, somente uma outra lógica. Se, na perspectiva objetivista de análise, a subjetividade aparece como desrazão, ela escapa à lógica racional: é inacessível, misteriosa. Quando a perspectiva alternativa aqui em discussão afirma a realidade da subjetividade, isto é, reconhece sua eficácia prática, ela descobre que a desrazão não é o contrário da razão mas uma outra racionalidade, com uma lógica diversa. Desse modo, porque tem uma lógica, ela torna-se inteligível. Por trás da aparência de irracionalidade, os universos simbólicos dos subalternos revelam sistemas lógicos de conhecimento. Ao trilhar o caminho que dá acesso ao entendimento desses sistemas, não se está fazendo a celebração de um enigma ou o elogio da emoção: "impõe-se, portanto, ao observador a necessidade de colocar-se em posição de compreender o significado das ações, postando-se, nas palavras de Paul Ricoeur, 'no centro do sentido procurado', buscando uma aproximação entre 'pensamento e vida', o que não implica em 'afinidade de vida a vida'. Em outras palavras, reconhecer - no caso do movimento do Contestado - que 'nos redutos tinha mistério'. Não para ficar dentro desse mistério, mas para entendê-lo como um sistema cuja ordenação é diferente da que prevalecia no mundo sem mistério que o rodeava" (Monteiro, 1974, p. 16).

No conjunto de trabalhos sobre culturas populares que marca a

6 Ver também Sorj (1989). 
produção acadêmica brasileira dos anos 70 e 80, busquei identificar a crítica ao entendimento das manifestações simbólicas subalternas enquanto produto da determinação estrutural, expressão do atraso das camadas populares e veículo de sua alienação. Como expus, em linhas gerais e através de exemplos selecionados:

1- a ênfase no campo de práticas não implica a rejeição absoluta das determinações estruturais, mas uma relativização que busca articular sujeitos e estruturas;

2- a ótica da experiência vivida permite uma leitura positiva do tradicionalismo de setores socialmente subalternos que não faz a apologia dos valores tradicionais, mas busca um entendimento racional de fenômenos cuja existência tem razões práticas, significativas e políticas;

3- a crítica à ideologia como falsa consciência não se desdobra na consideração das práticas culturais populares como expressão de uma consciência verdadeira, mas afirma a ambigüidade distintiva dos universos simbólicos populares.

A interpretação que se afirma através da revisão dos referenciais analíticos e políticos predominantes no cenário intelectual brasileiro retoma a questão da dominação e do conflito social em novas bases, a partir de uma abordagem antropológica que considera a dimensão simbólica da cultura. Ao invés de obscurecer o problema político, essa abordagem favorece uma formulação teórica ampliada da qual decorrem um conhecimento que atinge dimensões anteriormente inacessíveis e uma postura mais eficaz relativamente à atuação política do sujeito do conhecimento (científico) junto às camadas populares. Essas linhas mestras, aqui identificadas, desautorizam sua caracterização como uma perspectiva irracionalista que adere à sabedoria popular, abandona a racionalidade e rejeita a modernidade.

Na medida em que é possível defender o novo enfoque de um viés antiintelectualista não alinhado à modernidade, ele torna-se mais suscetível às críticas que vêm do outro extremo e que nele identificam novas tentativas de investimento no sujeito e no social, a despeito da desconstrução dessas categorias empreendida por vertentes contemporâneas alinhadas, em especial, às idéias de Michel Foucault. Os argumentos usados acima poderiam então servir à afirmação de seu comprometimento com uma nova figuração do social, ainda que heterogêneo, como referente fundamental da existência humana e da racionalidade geradora das identidades e da ação coletivas (cf. Teixeira, 1995).

O fato de que possa ser alvo de críticas que vêm de direções opostas no espectro de posições relativas à problemática da modernidade põe em relevo o caráter ambíguo dessa perspectiva analítica. Sua falta de unicidade, que se expressa inclusive na sua capacidade de abrigar, dentro de certos limites, uma considerável heterogeneidade de posições especificamente políticas, caracteriza-a como uma diretriz que comporta a indeterminação própria aos enfoques contemporâneos que oscilam incessantemente entre termos 
GARCIA, Sylvia Gemignani. Cultura, dominação e sujeitos sociais. Tempo Social; Rev. Sociol. USP, S. Paulo, 8(2): 159-176, outubro de 1996.

dicotômicos mantendo aberto, nesse movimento, um campo de possibilidades para pensar a ação coletiva na atualidade.

A meu ver, tal potencialidade se configura na contraposição à negação radical de toda positividade ao social buscada por aqueles que vêem no debate contemporâneo sobre as identidades de classe, gênero e etnia a continuidade do investimento moderno no social como fundamento do real, incapaz de incorporar as críticas à racionalidade moderna e de superar a abordagem das identidades políticas em termos de representação. A negação radical passa, assim, pela renúncia a qualquer pensamento que tenha em vista a ação em termos coletivos e chega à concepção de uma individualidade irredutível como única face possível do sujeito no mundo contemporâneo. Uma singularidade descolada de toda referência coletiva que vivencia a alteridade no registro do totalmente outro, na experiência do sublime, associada muito mais à estética do que à ética e à política. Buscando resgatar-se enquanto indivíduo de um social positivo que não cansa de engendrar subjetividades através de práticas de sujeição, essa diretriz tende por certo a renunciar a toda consideração pela dimensão coletiva da vida, desistência fortemente alimentada pela aguda consciência contemporânea da inelutável perversão de projetos históricos bem intencionados, da fatal degeneração das utopias em seu contrário. Fugindo ao objetivismo associado ao otimismo onipotente da razão iluminista, essa vertente tende a refugiar-se na figura do indivíduo autoengendrado retirando do horizonte da reflexão a problemática social e política.

Entre os dois extremos, a perspectiva analítica que se configura pela articulação entre universos simbólicos e relações de dominação fala de uma potencialidade cuja característica básica é que pode ser uma coisa e seu contrário ao mesmo tempo. Perspectiva fundamentalmente ambígua que propõe a indeterminação como regra e deixa aberto um espaço um tanto indefinido que abriga ainda a reflexão sobre o problema do poder sem submeterse necessariamente a ele, mas também sem ignorá-lo. Em um mundo marcado pelo paradoxo de uma crise de regulação social que não é acompanhada por uma crise de legitimidade (cf. Santos, 1994) e no qual crescem os níveis de desigualdade na mesma medida em que os desiguais desaparecem do discurso crítico, parece-me que essa potencialidade indefinida não é pouco.

Recebido para publicação em agosto/1996 


\section{UNITERMS: \\ culture, \\ domination, agency, structure, social order, sociology, anthropology, Brazil.}

GARCIA, Sylvia Gemignani. Culture, domination and social subjects. Tempo Social; Rev. Sociol. USP, S. Paulo, 8(2): 159-176, october 1996.

\section{REFERÊNCIASBIBLIOGRÁFICAS}

BILAc, E. Doria. (1978) Famílias de trabalhadores: estratégias de sobrevivência. São Paulo, Símbolo.

Branco, Glaucia V. B. Castelo. (1982) Sociologia e cultura: notas preliminares para uma revisão. Cadernos Ceru, São Paulo, 17(1), setembro.

BRANDÃo, Carlos Rodrigues. (1979) Deus te salve casa santa. Rio de Janeiro, Funarte.

. (1981) Sacerdotes de viola. Petrópolis, Vozes.

- (1982) Produtores tradicionais de cultura popular. Cadernos Ceru, São Paulo, 17(1), setembro.

. (1986) Os deuses do povo: um estudo sobre religião popular. São Paulo, Brasiliense.

BRUnI, José Carlos. (1980) Ideologia e cultura. (mimeo). São Paulo, FFLCH, USP.

CAldeira, Teresa Pereira do Rio. (1984) A política dos outros. São Paulo, Brasiliense.

Candido, Antonio. (1987) Os parceiros do Rio Bonito. São Paulo, Duas Cidades.

Chauí, Marilena. (1984) Seminários. O nacional e o popular na cultura brasileira. São Paulo, Brasiliense.

Durham, Eunice. (1973) A caminho da cidade. São Paulo, Perspectiva.

- (1977) A dinâmica cultural na sociedade moderna. Ensaios de Opinião, Rio de Janeiro, 4.

. (1980) A família operária. Consciência e ideologia. Dados, Rio de Janeiro, 23(2).

- (1986) A sociedade vista da periferia. Revista Brasileira de Ciências Sociais, São Paulo, 1(1), junho. 
Fernandes, Florestan. (1977) A sociologia no Brasil. Petrópolis, Vozes. . (1989) Ofolclore em questão. São Paulo, Hucitec.

Gramsci, Antonio. (1978) Concepção dialética da história. Rio de Janeiro, Civilização Brasileira.

. (1979) Literatura e vida nacional. Rio de Janeiro, Civilização Brasileira.

. (1985) Os intelectuais e a organização da cultura. Rio de Janeiro, Civilização Brasileira.

Lopes, J.S. Leite. (1984) Anotações em torno do tema condições de vida na literatura sobre a classe operária. In: SiLVA, L. A. Machado da (org). Condições de vida das camadas populares. Rio de Janeiro, Zahar.

Macedo, Carmen Cinira. (1979) A reprodução da desigualdade. São Paulo, Hucitec.

Magnani, José Guilherme Cantor. (1981) Cultura popular: controvérsias e perspectivas. Boletim Informativo Bibliográfico, Rio de Janeiro, 12.

MonteIro, Duglas Teixeira. (1974) Os errantes do novo século. São Paulo, Duas Cidades.

Montero, Paula. (1985) Da doença à desordem: a magia na umbanda. Rio de Janeiro, Graal.

Montes, Maria Lucia A (1983) Lazer e ideologia, a representação do social e do político na cultura popular. São Paulo, Tese (Doutoramento). Faculdade de Filosofia Letras e Ciências Humanas da Universidade de São Paulo.

OliveIRA, Francisco de. (1987) O elo perdido. São Paulo, Brasiliense.

ORTIZ, Renato. (1978) Cultura popular: organização e ideologia. (mimeo). Publicado em Cultura brasileira e identidade nacional com o título "Da cultura desalienada à cultura popular: o CPC da UNE". São Paulo, Brasiliense, 1985.

PAoli, Maria Célia. (1987) Os trabalhadores urbanos na fala dos outros. Tempo, espaço e classe na história operária brasileira. In: LoPEs, José Leite (coord.). Cultura e identidade operária. Rio de Janeiro, UFRJ/Museu Nacional/Marco Zero.

PÉCAUt, Daniel. (1990) Os intelectuais e a política no Brasil. São Paulo, Ática.

QueIroz, Maria Isaura Pereira de. (1981) Ainda uma definição do 'ser brasileiro'? Cadernos Ceru, São Paulo, 14(1).

SADER, Eder. (1988) Quando novos personagens entraram em cena. Rio de Janeiro, Paz e Terra. 
. \& Paoli, Maria Célia. (1986) Sobre classes populares no pensamento sociológico brasileiro. In: CARDoso, Ruth (org.). A aventura antropológica. Rio de Janeiro, Paz e Terra.

.\& Paoli, M.C. \& Telles, V.S. (1984) Pensando a classe operária: os trabalhadores sujeitos ao imaginário acadêmico. Revista brasileira de história, São Paulo, 6.

SAntos, Boaventura de Souza. (1994) Modernidade, identidade e cultura de fronteira. Tempo Social, São Paulo, 5(1-2), novembro.

Schwartzman, Simon. (1987a) Paradigma e espaço das ciências sociais. Revista Brasileira de Ciências Sociais, São Paulo, 2 (4), junho.

. (1987b)A força do novo: por uma nova sociologia dos conhecimentos modernos no Brasil. Revista Brasileira de Ciências Sociais, São Paulo, 2 (5), outubro.

. (1989) O gato de Córtazar. Novos estudos Cebrap, São Paulo, 25, outubro.

SoRJ, Bernardo. (1989) Crise e horizonte das ciências sociais na América Latina. Novos Estudos Cebrap, São Paulo, 23, março.

TeIXEIRA, Francisco Elinaldo. (1995) Entre o cristal e a fumaça: a condição social contemporânea. (mimeo). São Paulo, PUC. 